\title{
Construcción curricular en los nuevos espacios del diseño secundario. El Holocausto como propuesta de investigación en el Seminario de Ciencias Sociales
}

\author{
GUSTAVO DANIEL RAYNOLDI ${ }^{(1)}$
}

Fecha de recepción: 10/03/2020

Fecha de aceptación: 03/07/2020

Resumen. En este artículo analizamos algunos aspectos del nuevo espacio articulado para el nivel secundario: El Seminario de Ciencias Sociales. Su potencial innovador, y algunas tensiones detectadas entre el diseño curricular y su implementación, son abordados desde una experiencia con alumnos del segundo año de la Escuela Juan Marcos de la ciudad de Santa Fe; quienes trabajaron sobre estudios de caso vinculados a la Shoá, el proceso de persecución y exterminio del pueblo judío europeo ejecutado por el régimen nacional socialista del Tercer Reich alemán, antes y durante la Segunda Guerra Mundial. El diseño curricular del Ministerio de Educación de la Provincia de Santa Fe respecto al Seminario, el encuadre resolutorio que indica a nuestra jurisdicción educativa la incorporación de temáticas vinculada al Holocausto, y el Trayecto de Formación Docente sobre la Shoá de escala provincial, fueron tres factores que contribuyeron a fundamentar la elección de esta propuesta de enseñanza. La experiencia produjo movilizaciones en varios sentidos, que intentamos relacionar con el espacio todavía en construcción del Seminario, con la expectativa de realizar aportes en nuestra formación y práctica docente.

Palabras clave. Diseño curricular · Seminario · Shoá $\cdot$ interdisciplinariedad, investigación
(1) Licenciado en Historia de la Facultad de Humanidades y Ciencias de la Universidad Nacional del Litoral. Docente en las Escuelas Secundarias Juan Marcos $\mathrm{N}^{\circ} 3098$ y Victoriano Montes $\mathrm{N}^{\circ}$ 44I. Autor de: Mitre Historiador, 2006, publicado por la Junta de Historia de la Provincia de Corrientes. Primer premio del Concurso Nacional de Educación Superior organizado por la citada Junta y el Diario La Nación en los cien años del fallecimiento de Bartolomé Mitre. Autor de Tensiones politicas en el itinerario santafesino de José María Rosa, ponencia publicada en: Giletta, Carina; Carrizo, Bernardo (Compiladores), VIII Congreso Regional de Historia e Historiografia, 2017, UNL. gustanoldi@yahoo.com.ar 


\section{Curriculum Development for the New Areas Included in Secondary Education Contents. The Holocaust as a Research Proposal for Seminar of Social Sciences}

\begin{abstract}
This article deals with some aspects of the new articulated area for secondary level: the Seminar of Social Sciences. Its innovative potential and some tensions detected between curricular design and its implementation are addressed through an experience with students attending the second year of Juan Marcos Secondary School in the city of Santa Fe, Argentina, who worked on case studies about the Shoah, the process of persecution and extermination suffered by the European Jewish people under the national socialist regime of the German Third Reich before and during the Second World War. The curricular proposal was
\end{abstract}

defined according to the curriculum designed by the Provincial Ministry of Education in relation to the Seminar, the decisions of incorporating subjects related to the Holocaust in our educational jurisdiction, and the teaching training course on the Shoah offered by the provincial government. The experience brought about high motivation in various ways, which we tried to relate to the Seminar area that was still being constructed.

Keywords. curriculum design · seminar · Shoah . interdisciplinary - research

\section{Antecedentes y características del nuevo espacio}

La Ley de Educación Nacional del año 2006 constituye un proyecto de reforma educativa que intenta cambiar gran parte de lo establecido en la Ley Federal de Educación del año 1993. En función a ello, las provincias adaptaron sus diseños curriculares con algunos lineamientos básicos comunes, que a la vez reflejan sus propias improntas. La Provincia de Santa $\mathrm{Fe}$, en el año 2014 completó sus modificaciones con algunas propuestas innovadoras respecto a la tradicional atomización por materias. Una de ellas es la organización del Seminario de Ciencias Sociales.

Se otorgó libertad en la selección de contenidos, señalando que

La selección de dichos ejes se concretará en el ámbito de las decisiones pedagógicas de cada institución, dando cuenta de los intereses y problemáticas particulares de los estudiantes, como también de cuestiones locales que atraviesen la práctica escolar. Se sugiere como eje para el planteo de las problemáticas el conocimiento del pasado local, 
que puede abordarse a partir del análisis de fuentes primarias y secundarias, objetos, restos, testimonios, monumentos, escritos, conmemoraciones públicas, museos, filmografía. (Diseño Curricular de Educación Secundaria, 2014:101)

El Diseño señala también que pensar la realidad social es pensar en una complejidad de relaciones sociales y de influencias culturales, por ello el abordaje de la realidad social es necesariamente interdisciplinario. Pero la interdisciplinariedad resulta difícil de lograr ya que los docentes designados son profesores de Historia y Geografía, y las priorizan en sus clases, aunque se predispongan a abordajes más amplios. Se propicia la investigación como un compromiso colectivo y personal, pero los estudiantes cuentan con pocos instrumentos y destrezas para tratar problemáticas complejas, no están familiarizados con las diferentes disciplinas y no han sido formados en el método científico de investigación, como tampoco los propios docentes. (Baraldi, 2018:135,138-139)

Detrás de las actividades propuestas por un docente subyace su historia de vida, su itinerario educativo y su posicionamiento por un proyecto político-social. "La metodología desde la cual un docente se posiciona como enseñante está en gran parte imbricada con las perspectivas que él adopta en la indagación y la organización de su campo de conocimiento». (Edelstein, 1996) El docente define lo metodológico, y esto no es algo técnico, o una secuencia de pasos, sino un problema de la realidad a indagar. El contenido y el método se relacionan en los modos de proponer algo. No puede saberse todo de antemano, ya que lo metodológico es una construcción. Por otra parte el Seminario, que privilegia la comprensión, requiere un desarrollo de la comprensión propia del docente, porque «aprender a enseñar para la comprensión lleva tiempo, así como un compromiso y apoyo continuo» (Stone Wiske, 1999:30) Se genera un tópico generativo, un tema de interés, sobre el cual los alumnos realizan propuestas de trabajo y se definen metas de comprensión (Stone Wiske, 1999:311-33)

La tradicional impermeabilidad de la escuela frente a lo que ocurre más allá de sus aulas impide realizar clases interesantes. Pero el afuera ofrece múltiples oportunidades de aprender (Spiegel, 2007:45). En esta experiencia se visitó un lugar de memoria santafesino, en el cual tal vez muchos 
han estado sin reparar en su importancia. Fue transformado en un recurso didáctico para la tarea de enseñar y asumir compromisos éticos.

\section{Propuesta Temática}

La incorporación de la enseñanza del Holocausto-Shoá a los ámbitos educativos fue creciendo a nivel nacional y provincial. Lo observamos en los considerandos de la Resolución 1468 del año 2012 del Ministerio de Educación de la provincia de Santa $\mathrm{Fe}$, que hace referencia la Ley Nacional de Educación 26.206, la cual en su artículo 92 promueve contenidos que fortalezcan el Estado de Derecho, la vigencia de los Derechos Humanos y la construcción de la memoria colectiva. También alude a la Resolución 80/09 del año 2009 del Consejo Federal de Educación, que aprobó el Plan de Trabajo Enseñanza del Holocausto 2009/2011 a escala nacional; y en su artículo $2^{\circ}$ indica que «las autoridades educativas de cada jurisdicción se comprometen a incorporar contenidos curriculares acerca del Holocausto en los establecimientos educativos de dependencia». Ya en su aspecto decisorio, la Resolución provincial 1468 aprueba para Santa Fe el Programa de Formación Docente sobre la Shoá. En el año 2015, el Consejo Federal de Educación aprueba la Resolución 260/15 que en su artículo $1^{\circ}$ formaliza la creación de la Red Nacional de Educación y Memoria y el Programa de Educación y Memoria(2).

La Escuela Secundaria Orientada Particular Incorporada Nro. 3098 Juan Marcos, del barrio Acería de la ciudad de Santa Fe, una institución de gestión privada confesional cristiana evangélica auspiciada por la Asociación Civil de la Iglesia Rayo de Luz, en el año 2018, con alumnos de segundo año del Ciclo Básico, turnos mañana y tarde, introdujo en el espacio del Seminario esta propuesta temática de investigación, teniendo en cuenta que

Existen diversas formas de comprender este proceso histórico, y estos modos han cambiado a lo largo del tiempo, y gracias al aporte de nuevos documentos y estudios de académicos de diversas disciplinas. Hoy es ampliamente aceptado el contenido universal del Holocausto, que incluyó fenómenos como la ideología totalitaria, estado moderno, mecanismos burocráticos de dominio, sistemas bélicos sofisticados, campos de concentración, fenómenos cuya naturaleza la humanidad continúa experimentando. La otra razón es la
(2) La Red Nacional se conformó con referentes de todas las jurisdicciones educativas. El Programa Educación y Memoria se establece para decidir sobre desarrollo curricular, capacitación docente, materiales educativos y proyectos de trabajo, ofreciendo apoyo a los proyectos provinciales, como en el caso de Santa Fe. 
particularidad de las víctimas del holocausto, los judíos, y la violencia de los contenidos políticos, raciales y antisemitas proyectados sobre los mismos como consecuencia de su singularidad histórica en el mundo occidental. Es para nosotros los docentes, un imperativo recuperar esas voces que ya no están y que desde la ausencia se hacen presentes para recordarnos el horror (Resolución 1468, 2012)

\section{Desarrollo de la experiencia}

Dada la escasa formación de los alumnos, que antes señalamos y parece poco previsto en el diseño curricular, la primera parte del ciclo lectivo intentamos alcanzar nociones básicas sobre el objeto de las ciencias sociales, sus orígenes y características, la metodología de la investigación, los recortes temáticos y temporales, los tipos de fuente y su tratamiento. Luego del receso invernal, atendiendo al carácter colectivo y colaborativo del Seminario, dividimos el curso en grupos de investigación y realizamos la propuesta temática, que sería abordada desde estudios de caso elegidos por ellos. Podían ser historias de sobrevivientes, campos de concentración, o personas que ayudaron a las víctimas. Los casos debían contextualizarse históricamente. Desde la geografía se pudo identificar el área general del proceso y de cada caso particular estudiado, dando cuenta de las modificaciones que las actividades humanas imponen al espacio. También surgieron cuestiones lingüísticas y éticas al abordar ideologías, discursos, prejuicios, valores, y el problema filosófico del sentido de lo ocurrido, vinculado a asignaturas como Formación Ética y Ciudadana y Lengua. Solo el tristemente célebre eufemismo solución final permitió cierto análisis interdisciplinario, en tanto refleja, junto a otras expresiones, cierta degradación de la lengua para decir algo inexpresable, (exterminio de un pueblo) y que se vincula a cuestiones históricas, raciales e ideológicas. Desde la Música se coordinaron interpretaciones musicales en danza, y la Tecnología aportó una mirada sobre el desarrollo de la industria nazi puesta al servicio del exterminio masivo. La propuesta de esta temática universal no contradijo la sugerencia de conocer el pasado local, ya que, como veremos, en buena medida se logró armonizar ambas dimensiones. Cada grupo expuso sus primeros avances, presentando 
sus fuentes de información, familiarizándose con conceptos como «nazi», "antisemitismo», "campo de concentración» y "Shoá»(3), entre otros.

Acercándose el fin del ciclo lectivo, se solicitó una monografía que registre lo trabajado por cada grupo. Dada la dedicación observada, decidimos realizar un acto de cierre donde los alumnos expusieran sus conclusiones. Surgió también la idea de aprender y cantar juntos la canción Sobreviviendo, del cantautor argentino Víctor Heredia, con soporte musical de los propios alumnos, quienes también formaron un grupo de danza que interpretó la melodía Caricia sobre el Océano(4), parte del fondo musical del film Los Coristas, para expresar de otra manera los sufrimientos de las víctimas. Previo al cierre de las investigaciones, se puso en conocimiento de las actividades que realizábamos a la profesora Eugenia Rizzo de la Escuela Judía Bialik de Santa Fe, encargada del Equipo Organizador del Trayecto de Formación Docente: Enseñar la Shoá. Entre el conocimiento y el recuerdo-una ética del cuidado del otro, organizado por DAIA ${ }^{(5)}$ Santa Fe y el Ministerio de Educación Provincial, y que tuve la oportunidad de realizar. Nos alentó a seguir trabajando y planteó como posible actividad que los estudiantes elijan y propongan un nombre para que sea inscripto en el Paseo de los Justos entre las Naciones ${ }^{(6)}$ emplazado en la costanera santafesina, como una forma de acercamiento a un lugar de memoria.

\section{Derivaciones fructíferas}

En el curso del año 2019, con los alumnos ya en tercer año, recibimos esta propuesta formal, la cual originó una movilización en varios sentidos. Hacia dentro de la institución escolar, directivos/docentes/alumnos interesados en cumplir el rol que se nos asignaba como reconocimiento a nuestro interés. Hubo también un acercamiento entre instituciones educativas, entre la Escuela Bialik y Juan Marcos lo cual también representó, indirectamente, un acercamiento entre la comunidad judía y evangélica local ${ }^{(7)}$, que organizaron un primer encuentro en un acto formal, donde nuestros alumnos fundamentaron la elección del nombre de la misionera cristiana holandesa Cornelia Ten Boom, (conocida por el diminutivo de su nombre de pila
(3) Se intenta instalar el uso del vocablo hebreo Shoá para reemplazar a Holocausto. El Holocausto es una ofrenda de la tradición judía que supone un sacrificio voluntario a Dios, algo totalmente ausente en las víctimas del genocidio. Shoá significa devastación y obviamente la palabra es más adecuada

(4) Canción del compositor francés Bruno Coulais, autor de la Banda Sonora de la película francesa del año 2004, conocida en Hispanoamérica como Los Coristas, musical dramático dirigido por Christophe Barratier.

(5) Delegación de Asociaciones Israelitas argentinas

(6) La institución Yad Vashem, creada por el Estado de Israel para honrar a las víctimas y héroes del Holocausto distingue con el título de Justo entre las Naciones a personas que sin ser de confesión o ascendencia judía, prestaron una ayuda altruista a las víctimas. De allí el nombre del Paseo santafesino.

(7) Ubicadas al sur y al noroeste de la ciudad, aunque difieren en sus creencias y trasfondos socioeconómicos, realizaron un trabajo educativo conjunto basado en valores comunes. Ver también noticia del segundo encuentro, recuperado de: https://www.radiojai.com/ index.php/20I9/II/27/31855/ el-homenaje-a-una-justaentre-las-naciones-que-une-ajovenes-evangelicos- $y$-judios/ 
(8) Corrie Ten Boom fue reconocida en vida, en el ańo 1967, como Justa entre las Naciones. Su padre Casper y su hermana Elisabeth, póstumamente también fueron distinguidos como tales en el año 2007 (Registro de la institución Yad Vashem sobre la familia Ten Boom) (9) La Escuela Juan Marcos fue fundada hace tres décadas por el pastor evangélico Julio Caraffa, y cuenta con todos los niveles del sistema educativo: inicial, primario, secundario y terciario.
Corrie). Ella albergó con su familia, durante la Segunda Guerra Mundial, a un gran número de judíos y otros perseguidos políticos, salvando a más de ochocientas personas ${ }^{(8)}$. Su familia pertenecía a la Iglesia Reformada Holandesa y Corrie fue educada en el amor a Dios, al prójimo, muy distante del prejuicio antisemita. Al ser descubiertos por los nazis fueron arrestados, falleciendo al poco tiempo su padre en prisión. Corrie y su hermana Betsy fueron deportadas al campo de concentración de Ravensbrook, donde su hermana falleció. Corrie sobrevivió a la guerra y se tornó una misionera cristiana. En su libro El Refugio Secreto, narra sus experiencias durante la ocupación alemana de Holanda.

Los alumnos de la Escuela Bialik, quienes propusieron la base de nombres con que el Paseo ya contaba, nos hicieron partícipes de otras iniciativas valiosas, y el momento se cerró con representaciones musicales en danza y un productivo intercambio entre alumnos, directivos, docentes y ministros religiosos de ambas comunidades.

En este clima nos informaron de la inminente visita a Santa Fe de Hélène Gutkowski, sobreviviente de la Shoá en la Francia ocupada por los nazis, para presentar su último libro (Gutkowski, 2019), en el marco del aniversario de La Noche de los Cristales Rotos, primer ataque masivo de los nazis contra los judíos. Hélène, actualmente con 77 años, nació en París en 1942 y tuvo que ser entregada por sus padres al cuidado de otra familia para ocultar su identidad judía. Se reintegró a su hogar original luego de la guerra a la edad de ingreso a la escuela primaria. Llegó a Argentina en 1961, se graduó de Socióloga y desarrolló una carrera como escritora y en talleres de memoria. Fue invitada a dar su testimonio en la Escuela Juan Marcos y tuvo la deferencia de reservar un espacio entre sus compromisos. Se convocó a los cursos de primaria y secundaria(9), y la mayoría escucharon por primera vez a un sobreviviente de la Shoá.

No solo debemos recuperar las voces de las víctimas que ya no están, también revalorizar a los sobrevivientes/testigos, los que están, dando sentido a su estadía entre nosotros. A ello nos instan las nuevas manifestaciones de antisemitismo y negacionismo, los nacionalismos exacerbados y los discursos xenófobos alarmantes que se consolidan desde nuevas posturas políticas, étnicas y religiosas. 
Espacios institucionales extraescolares tales como DAIA filial Santa Fe y la Municipalidad de Santa Fe colaboraron para establecer el Paseo de los Justos entre las Naciones como espacio público de memoria ${ }^{(10)}$, abriéndolo a la realización de este evento educativo en una conmemoración. Es un lugar prácticamente único en Latinoamérica ${ }^{(11)}$, enmarcado en la costanera santafesina. En sus inmediaciones la población disfruta momentos de esparcimiento. Allí se rinde homenaje a personas no judías de distintas nacionalidades que, arriesgando y muchas veces perdiendo sus propias vidas y seguridades, salvaron personas de una maquinaria de muerte. Acercándose el $81^{\circ}$ aniversario de La Noche de los Cristales Rotos ${ }^{(12)}$, el 9 de noviembre de 2019, se pensó que sería una fecha oportuna para la inscripción del nombre propuesto. El homenaje sería encabezado por el intendente de la ciudad de Santa Fe y el presidente de la DAIA local. Los medios de comunicación constituyeron otro factor extraescolar que contribuyó a dar difusión a las actividades antes, durante y después de las mismas ${ }^{(13)}$. Recuerdo la emoción de nuestros alumnos al pensar que serían escuchados por autoridades gubernamentales e institucionales en un acto público, siendo tenidos en cuenta para sumar un nombre a la ciudad, participando en algo significativo que perdurará socialmente. Se sintieron visibilizados en sus trabajos escolares al lograr incorporar una medida de valores esenciales a la convivencia social, así como una mayor conciencia del daño que produce el abandonarlos. Cabe destacar el trasfondo socioeconómico vulnerable de nuestros alumnos, en muchos casos provenientes de familias de constitución atípica y características disfuncionales; adolescentes que padecen vacancias afectivas y materiales. Superficialmente podría pensarse que ello podría inhibir su interés por los efectos del racismo desatado en Europa hace setenta años. Pero las investigaciones produjeron una transposición didáctica, y el aprendizaje no quedó dislocado al momento de apropiarse subjetivamente de los contenidos. El estudio del pasado se tornó para ellos también un problema del presente, ampliando su comprensión y compromiso, jerarquizando sus aportes e integrando espacios. Junto al intendente y otras autoridades civiles $^{(14)}$ y religiosas los alumnos descubrieron la placa de la homenajeada y plantaron un cerezo en su memoria, como símbolo de que a través de su sacrificio la vida puede continuar.
(10) DAIA destacó el Paseo de los Justos. Recuperado de: https://www.sinmordaza.com/ noticia/76I467-daia-destaco-elpaseo-de-los-justos-entre-lasnaciones.html

(11) En los museos y lugares de memoria del Holocausto se recuerda principalmente a las víctimas. La singularidad del Paseo está dada en que es un lugar de homenaje a quienes ayudaron a las víctimas. (12) En alemán KristallNacht o November pogrome (pogrom de noviembre). Con estos nombres se conocen a una serie de linchamientos y ataques combinados llevados a cabo por los nazis en Alemania y Austria contra ciudadanos e instituciones judías durante la noche del 9 al io de noviembre de 1938 .

(13) Homenaje a una justa holandesa, Telefé Santa Fe. Recuperado de: https://youtu. be/hkbAk7eyAYU.

(14) Se encontraban presentes también el Secretario de Derechos Humanos y el Secretario de Educación de la Provincia de Santa Fe, y el presidente de la DAIA central de Buenos Aires. 
(15) Una evaluación en proceso y de diagnóstico continuo. El espacio se acredita con instrumentos acordes a la modalidad, y en momentos que se considere pertinente. Se recomienda no acreditar los espacios articulados en mesa examinadoras de diciembre/ febrero, sino al final del ciclo lectivo.

\section{Reflexiones finales relativas a la construcción curricular}

Aunque la fuerte temática del Holocausto fue abordada por alumnos cuyas edades oscilaban entre los 14 y 16 años, el recorrido histórico contribuyó a su formación ética y democrática. No obstante los problemas señalados en cuanto a la interdisciplinariedad, consideramos que estuvo presente en un nivel exploratorio, posibilitando elaborar propuestas más ambiciosas. En cuanto a la investigación, el carácter colectivo y colaborativo propio del Seminario pudo concretarse, y hubo un acercamiento al pasado con recursos sólidos que involucraron dimensiones universales y locales. Entre las fuentes sugeridas en el Diseño Curricular, en este caso tuvieron especial impacto los escritos, testimonios y conmemoraciones públicas. El lugar de memoria reemplazó a su equivalente museos. Los criterios evaluativos se apegaron a los lineamientos del Programa Secundario Completo de la Provincia de Santa Fe ${ }^{(15)}$

El docente no es un «mero instrumento o agente de transmisión» de lo prescripto, ya que «aquello que se prescribió en el papel se va modelando, enriqueciendo, modificando a partir de los movimientos que genera el desarrollo del programa» (Bernik, 2003:18,21) El espacio del Seminario, aunque con dificultades, poco a poco se abre camino. Terigi señala la existencia de un «trípode de hierro», que resiste propuestas innovadoras en tres niveles: a) Disciplinar-curricular. b) En la formación de los docentes por disciplina c) En la estructura de horas cátedras (Baraldi, 2018:127). El Seminario enfrenta una enseñanza fragmentada y estructurada por materias, muchas veces con poca relación entre ellas. Los docentes están muy ocupados al frente de sus horas cátedras en diferentes instituciones; y, además de su poco tiempo disponible, no han sido formados para abordajes multidisciplinarios. Pero el inventario de esta experiencia ha interesado a directivos y docentes de la Escuela Juan Marcos, quienes comenzaron a diseñar un proyecto institucional interdisciplinario vinculado a la enseñanza de la Shoá para el segundo año del Ciclo Básico. La temática ya se incorporó formalmente a su planificación anual, y el proyecto involucrará a docentes de varias asignaturas, para encontrar puntos de acuerdo, realizar diagnósticos, trabajar sobre contenidos curriculares comunes y vertebrar propuestas que puedan gestar enfoques al interior de cada área disciplinar y materia, fortaleciendo a la vez 
una mirada integral más amplia. También se realizaron modificaciones a las planificaciones del Seminario de primero y segundo año, ya que no existía entre ellas una articulación que denote una continuidad curricular clara en sus objetivos, contenidos y metodología. Trabajar sobre ello permitirá que, al realizarse las investigaciones del segundo año, se encuentren con una mejor base previa, los trabajos presenten mayor solidez, y la trayectoria pedagógica entre primero y segundo año sea más progresiva y gradual en secuencia y profundidad. Los contenidos, sin embargo, son solo un aspecto del curriculum, que incluye otros factores que inciden en su alcance o reconfiguración. Las características de los adolescentes, sus intereses/indiferencias por alumno y curso, requieren adaptaciones diversas. Las derivaciones, frustraciones y logros gravitan sobre la construcción del curriculum real.

Estas consideraciones al interior del Ciclo Básico podrían tenerse en cuenta también para el Seminario en los años del Ciclo Orientado, ya que persisten problemáticas y posibilidades comunes a todo el secundario. El número de materias vinculadas a las ciencias sociales aumentan en el Ciclo Orientado, permitiendo más enfoques y colaboración conjunta desde/con el Seminario; desafío que se afrontará en mejores condiciones si el recorrido del Ciclo Básico brinda aprendizajes significativos. Socializamos esta experiencia para convalidar una propuesta que se corresponde con las expectativas formales del espacio, desarrollar sus potencialidades, resolver tensiones observadas entre el diseño curricular y su implementación, y realizar aportes que contribuyan a mejorar nuestra formación y práctica docente. 


\section{Referencias bibliográficas}

Baraldi, Victoria y otros (2018). Definiciones, interpretaciones y tensiones en la configuración de los nuevos espacios curriculares. El caso del Seminario de Ciencias Sociales, en Baraldi, Victoria (Comp.), Educación Secundaria Orientada en Santa Fe. Sujetos y Construcción Curricular en el Ciclo Básico (p. 127, 135, 138-139), Santa Fe: Ediciones UNL.

Bernik, J. (2003). Sobre la noción de programa. Cuadernillo del Módulo Final de Integración. Ciclo de Capacitación en Docencia para Profesionales, Facultad de Humanidades y Ciencias, Centro Multimedial de Educación a Distancia (CEMED). Santa Fe: Ediciones UNL. Edelstein, G. (1996). Un Capítulo Pendiente, el Método en el Debate Didáctico Contemporáneo, en W. de Camilloni A. y otros, Corrientes Didácticas Contemporáneas (p. 75-90). Buenos Aires: Paidós.

Gutkowski, H. (2019). Querido país de mi infancia: memorias entrelazadas de niños que sobrevivieron en la Francia ocupada y emigraron a la Argentina. Buenos Aires: Libros El Zorzal.

Spiegel, A. (2007). Planificando clases interesantes, Buenos Aires-Méjico: Ediciones Novedades Educativas.

Stone Wiske, M. (Comp.) (1999). La enseñanza para la comprensión, Buenos Aires: Paidós

Terigi, F. (2008). Los cambios en el Formato de la Escuela Secundaria Argentina: Por qué son necesarios. Por qué son tan difíciles. Recuperado de https://pdfs.semanticscholar.org/4880/e32492a02524945578429d6ca163d100498b.pdf

\section{Documentos}

Ministerio de Educación de la Nación (1993). Ley Federal de Educación 24.195. Recuperado de https:// www.buenosaires.gob.ar/sites/gcaba/files/ley_24195. pdf

Ministerio de Educación de la Nación (2006). Ley de Educación Nacional 26.206, art. 92 Recuperado de: https://leyes-ar.com/ley_de_educacion_nacional/92.htm Consejo Federal de Educación (2009). Resolución 80/09. Recuperado de: http://www.bnm.me.gov.ar/ giga1/normas/13867.pdf

Ministerio de Educación de la Provincia de Santa Fe (2012). Resolución 1468. Recuperado de: www. santafe.gov.ar/index.php/educacion/content/download/154724/755039/file/Res 1468-12

Ministerio de Educación de la Provincia de Santa Fe (2014). Diseño Curricular de Educación Secundaria Orientada, (p. 98-101) Recuperado de: https:// www.santafe.gov.ar/index.php/educacion/content/ download/218364/1135170/file/Anexo\%20II\%20 Resol\%202630-14.pdf

Consejo Federal de Educación (2015). Resolución 260/15, Programa Educación y Memoria. Recuperado de: http://www.bnm.me.gov.ar/giga1/normas/ RCFE_260-15.pdf

Ministerio de Educación de la Provincia de Santa Fe (2017). Programa Secundario Completo. Recuperado de https://plataformaeducativa.santafe.edu.ar/moodle/ secciones/programa_destacado.php?id=34 